\title{
Influence of wood flour and modifier contents on the physical and mechanical properties of wood flour-recycle polypropylene composites
}

\begin{abstract}
The objectives of this research was to evaluate the physical and mechanical properties of composites of Wood Flour (WF) and Recycle Polypropylene (RPP) prepared under various WF contents, WF sizes and modifier contents. WF from mixed-soft wood species and Eucalyptus deglupta Blume species were used as filler. The composites composed of 0-70\% WF, 0-70\% Polypropylene (PP) or RPP, various sizes of WF (60-80; 80-100 and < 120 mesh), various contents of MAH modifier $(0,1,2.5,5,7.5$ and 10\%) and 15\% Dicumyl Peroxide (DCP) initiator (based on MAH weight). Kneading conditions were set at $170{ }^{\circ} \mathrm{C}$, $10-50 \mathrm{rpm}$ for $15 \mathrm{~min}$. The physical and mechanical properties of composites were greatly affected by WF content, WF size and modifier content. The greater the WF loading resulted in the greater was the reduction of tensile strength and breaking elongation values and at the same time the greater was the increasing of Young`s modulus value. The smaller the WF size resulted in the greater the tensile strength of composites. Addition of MAH modifier improved the physical and mechanical properties of composites. WF-RPP composites with 120 mesh WF size and 2.5\% MA modifier had tensile strength, breaking elongation and Young`s modulus about 2.15, 2.27 and 1.18 times, respectively higher compared with composites free-MAH modifier and absorbed considerably less water. Scanning Electron Microscope (SEM) indicated that addition of MAH improved the adhesion between WF and RPP.
\end{abstract}

Keyword: Wood flour, recycle polypropylene, composite, modifier 